\title{
EL ALMA ÚNICA Y UNIVERSAL HEREDERA DEL PATRIMONIO RÚSTICO DE DON PEDRO DE GRANADA VENEGAS MANRIQUE DE MENDOZA, PRIMER MARQUÉS DE CAMPOTÉJAR $(1643)^{1}$
}

\author{
HIS IMMORTAL SOUL AS UNIVERSAL HEIR TO THE COUNTRY \\ ESTATES OF DON PEDRO DE GRANADA VENEGAS MANRIQUE DE \\ MENDOZA, FIRST MARQUIS OF CAMPOTEJAR (1643)
}

\author{
José Antonio García LujáN \\ Universidad de Córdoba \\ ca1galuj@uco.es
}

RESUMEN: A partir de documentos inéditos existentes en diversos archivos públicos se analiza el notable patrimonio rústico que don Pedro de Granada Venegas Manrique de Mendoza, titular de los mayorazgos y Casa de Granada desde 1611 y primer marqués de Campotéjar, formó desde finales del siglo XVI hasta su fallecimiento en 1643, que por falta de descendencia legó a su alma como única y universal heredera. Se distinguen las propiedades rústicas inalienables del mayorazgo de aquellas otras que adquirió en su larga vida, ya como bienes personales propios, ya en régimen de gananciales. Se analizan todas ellas y sus características: nombre, situación, superficie, compra, tasación y valor. Asimismo, sus cultivos, elementos, gestión del patrimonio rústico y rentas que generaban en cereales y adehalas. El resultado es el primer estudio sobre la hacienda agraria privada, no vinculada al mayorazgo, de la Casa de Granada centrado en su quinto titular y primer marqués de Campotéjar.

PAlABRAS ClAVE: Historia agraria; cultivos; marquesado de Campotéjar; siglo XVII; Casa de Granada.

ABSTRACT: Through the study of a number of unpublished documents from various public archives, this article examines the large number of country estates that Don Pedro de Granada Venegas Manrique de Mendoza, owner of the entailed estates and the House of Granada, accumulated between the end of the $16^{\text {th }}$ century and the year of his death in 1643 and which, because he had no descendents, he bequeathed to his soul, as his one and only heir. We make a distinction between

1. Abreviaturas utilizadas: AGS, = Archivo General de Simancas; AHN, = Archivo Histórico Nacional; AHPNM, = Archivo Histórico de Protocolos Notariales de Madrid; AMJ, = Archivo del Ministerio de Justicia; ARCGr, = Archivo de la Real Chancillería de Granada; BNE, = Biblioteca Nacional de España; doc, = documento; leg, = legajo; ms, = manuscrito; mrs. = maravedís; núm, = número. 
his entailed estates and those he acquired personally. In this article we study these latter estates -their names, situation, size, purchase, price and value. We also study what crops were grown, the administration of the properties, and the rents and profits they produced. This is the first study to be carried out of the private, personal estate, as opposed to the entailed estate, of the House of Granada, where Don Pedro de Granada Venegas Manrique de Mendoza was the fifth owner and first Marquis of Campotéjar.

KEYWORDS: agrarian history; crops; Marquisate of Campotéjar; $17^{\text {th }}$ century; House of Granada.

Son fuentes documentales básicas, entre otras, para este trabajo el testamento y codicilos ${ }^{2}$, el inventario judicial de bienes, tasación de los mismos y adjudicación a los herederos ${ }^{3}$, la fundación de Patronato y Obra Pía e hijuela de los bienes que se le asignaron ${ }^{4}$ y autos para la toma de posesión ${ }^{5}$ atinentes todos ellos a don Pedro de Granada Venegas Manrique de Mendoza, primer marqués de Campotéjar. Completa descripción y valoración de todos sus bienes agrarios, tanto los pertenecientes al mayorazgo de la Casa de Granada como los libres, privativos y gananciales, que poseyó en su larga vida. Este sólido patrimonio raíz personal lo convirtió en gran propietario y, junto con otras importantes fuentes de ingresos no agrarias, acrecentó su posición social y nobiliaria permitiéndole el desempeño brillante de altos cargos en la Corte, a la que, como otros nobles, se trasladará en pos de influencia y dinero integrándose en la élite de poder ${ }^{6}$.

\section{El HOMBRE Y SU LINAJE. EL PATRIMONIO VINCULADO}

En reconocimiento de su persona y cargos ejercidos, Felipe IV tituló a don Pedro de Granada Venegas con el vizcondado de Miravalles en 1632; este poco después representó al monarca los servicios prestados por sus antecesores a la Monarquía Católica y los suyos propios solicitando la dignidad de marqués para su Casa, ruego que atendió el soberano con la denominación primero de Camporrey, uno de los cortijos que poseía, y posteriormente de Campotéjar, lugar del que era señor jurisdiccional ${ }^{7}$. Memorial en el que relaciona el desempeño de oficios palatinos - menino de la reina Ana de Austria, mayordomo de la reina Isabel de Borbón, gentilhombre de boca del monarca reinante y de su predecesor, miembro del Bureo y Casa de la Reina-, así como militares y civiles durante seis décadas: participante en la Jornada de Portugal y entrada en Lisboa en 1582, donde se ofreció

\footnotetext{
2. AMJ, Título de Marqués de Campotéjar, doc. 75.

3. AHPNM, leg. 8.213.

4. AHN, Consejos, leg. 25.993, doc. 2.

5. AHN, Consejos, leg. 25.993, doc.3.

6. Maravall 2007; Domínguez Ortiz 1985; Álvarez-Osorio Alvariño 1998.

7. García Luján 2002.
} 
al monarca para ir junto con otros caballeros a la conquista de Nuevo México ${ }^{8}$; auxilio de Almería frente al rey de Argel en 1584, y de Adra ante un asalto norteafricano en 1620; enviado eficaz del soberano al cabildo de Granada en varias ocasiones para obtener su apoyo; rechazo a una escuadra de navíos ingleses siendo alcaide Salobreña en 1596, año en que pasó a servir la de Almuñécar; asistente al casamiento de Felipe III y Margarita de Austria en Valencia y al nacimiento del futuro heredero en Valladolid hasta que la Corte volvió a Madrid en 1606; procurador por Granada en las Cortes de Madrid de 1608, cuyo parecer fue decisivo para otorgar al monarca el servicio de veinte millones que solicitaba; corregidor de Ávila en 1611, cargo no deseado pero obligado a ejercerlo por mandato regio?. Una vinculación a la Corte mediante empleos palaciegos y de gobierno con los que incrementó el prestigio de su Casa y de sí mismo.

La milicia y la Corte, junto con la creación de un gran patrimonio, fueron los ejes vitales de don Pedro de Granada Venegas Manrique. Otorgó testamento cerrado en Madrid el 14 de mayo de 1642, y sendos codicilos el 5 de noviembre de ese año y el 25 de enero de 1643, dejando por mi única y unibersal heredera de todos mis bienes a mi alma, para cuyo venefiçio y hacer bien por ella y las de mis difuntos ynstituyo y ago una obra pía y patronato perpetuo ${ }^{10}$.

El punto de partida de don Alonso Venegas, segundo titular de la Casa, fue la habitual donación de tierra a los capitanes en la conquista del reino de Granada, 810 fanegas concedidas por la Corona en Campotéjar ${ }^{11}$ que incrementó con la compra a sus vecinos, roturación y ocupación de tierra despoblada, donde estableció grupos de campesinos ${ }^{12}$ de quienes era, si no de iure sí de facto, señor y como tal se intitula a sí mismo; señorío jurisdiccional que alcanzará su biznieto don Pedro de Granada Venegas Manrique un siglo más tarde, con el que reforzó su nobleza y pudo ostentar un título de Castilla.

En una relación de los bienes que poseía en 1522 don Alonso Venegas se mencionan los cortijos de Campotéjar, Garnafate, Dehesa Vieja, Faucena, Pozuelo, Moreda, Telera y heredades en Moclín, propiedades todas con una superficie de 3.367,75 ha. en la comarca de los Montes Orientales, parte septentrional del alfoz de Granada, así como una viña en Albolote y una hacienda en la ciudad de Grana$\mathrm{da}^{13}$. Obtenida licencia regia, don Alonso en su carta de mayorazgo de 1533 asignó como bienes rústicos vinculados la alquería, venta y cortijo de Campotéjar, las alquerías y cortijos de Dehesa Vieja Alta y Baja, Garnafate, Hoya el Puerco y El Juncal, y en Granada la Huerta del Campo ${ }^{14}$.

8. Cabrera de Córdoba 1998, p. 991.

9. BNE, Manuscritos, ms. 17.605, núm. 20. Su trayectoria vital es analizada en detalle por Álvarez Márquez, García Luján, 2008, pp. 149-158, estudio al que me remito.

10. Cláusula cincuenta y tres del testamento.

11. Casey 2008, p. 111. El origen nazarí y el linaje Granada Venegas desde 1432 a 1660 en García Luján 2010, pp. 13-43.

12. Peinado Santaella 1989.

13. Peinado Santaella, Osorio Pérez 2006, p. 278.

14. García Luján 2010, p. 30. 
La propiedad de estos cortijos amayorazgados, más el cortijo de la Solana, fue cuestionada ante los tribunales entre 1540 y 1564 por el Ayuntamiento de Granada contra don Pedro de Granada Venegas Mendoza, hijo de don Alonso y sucesor en la Casa, sin que hubiera una sentencia firme y ejecutiva al respecto ${ }^{15}$. El hecho cierto es que un año después don Alonso de Granada Venegas Rengifo, nuevo titular de la Casa y mayorazgo, mediante apoderado tomó posesión de todos ellos señalando alguna de sus características: Campotéjar, cortijo con tierras, monte y algunas casas con plaza por la que se paseó; Garnafate, cortijo y tierras de riego y secano con algunas casas y unas yuntas arando en una haza, que mandó parar en señal de posesión; el Juncal, cortijo cerca del de Garnafate, linderos uno con otro, cuyo labrador Lorenzo Çujayarí, cristiano nuevo, vivía en una casa del mismo; Dehesa Vieja, cortijo con granero de varias cámaras con llave, casas, en una de las cuales residía Miguel Carabaquí, cristiano nuevo, vecino de Nívar y labrador junto con otros cristianos nuevos; la Solana, cortijo en Dehesa Vieja con casas, una de ellas habitada por Miguel Alaxib y su hijo, cristianos nuevos, labradores además de otros ${ }^{16}$.

Este gran fundo, inalienable por ser mayorazgo, que recibió don Alonso de Granada Venegas Rengifo fue el mismo que transmitió a su hijo y sucesor. En nada lo incrementó devorado por las deudas y censos que pesaban sobre su Casa, y en corta medida aumentó sus bienes raíces libres con la compra de las encinas y quejigos de Campotéjar y Jayena a la Hacienda Real ${ }^{17}$ por 5.000 ducados $^{18}$.

\section{LA FORJA DE UN GRAN PATRIMONIO RÚSTICO}

A diferencia de su progenitor, don Pedro de Granada Venegas Manrique, primer marqués de Campotéjar, dejó al morir un gran patrimonio personal propio y de gananciales en activos financieros, bienes muebles e inmuebles, urbanos y rústicos. Interesan ahora solo estos últimos que evidencian la ruralización de la sociedad y economía granadinas, fenómeno común a otras muchas zonas del reino de Castilla, y la mentalidad rentista y nobiliaria de la época. Los bienes que adquirió y su localización fueron:

- La Huerta Nueva, llamada otras veces Huerta del Campo, en el pago de Pizarrama en la Vega de Granada, lindera con el camino a Santa Fe y la Huerta del Pilar de don Pedro, mayorazgo de la Casa; eran 53 marjales de huerta $^{19}$, arrendada en 50 ducados, tasado el marjal en 22 ducados.

15. Peinado Santaella 1989b, pp. 168-170.

16. ARCGr, caja 10 , pieza 1 , ff. $616 \mathrm{v}-627 \mathrm{r}$.

17. 4 de febrero de 1590 .

18. Salamanca López, Blázquez Ruz 2002.

19. Comprada a Pedro Fernández de Córdoba, ejecutor real, en la venta judicial de los bienes de Pedro Fernández de Córdoba el 13 de mayo de 1594. 
- 48 fanegas de secano, llamadas Baldíos ${ }^{20}$, que habían sido de moriscos, por debajo del Generalife, linderos entre este, la Acequia del Rey y los cármenes del marqués del Carpio y de Navas, valorados en 24.057 mrs.

- Media suerte de población en Restábal, valle de Lecrín, con casa, huerto y agua, comprada ${ }^{21}$ por 80 ducados y tasada en la misma cantidad.

- 40 fanegas de tierra en Salobreña junto a la fuente llamada de don Pedro, donación de la villa siendo alcaide de la fortaleza por el repartimiento que hizo a los vecinos de tierra para viñas y árboles, y en agradecimiento por la cédula real que obtuvo para ello; plantadas de viñas, a las que unió otra heredad ${ }^{22}$.

- La hacienda de Cordobilla ${ }^{23}$, a 2 leguas de Almuñécar, con 17.000 vides, 3.000 árboles, casa y ermita que edificó con la advocación de Nuestra Señora de los Castillejos, justipreciada en 200 ducados.

- Bancales de tierra de riego, pequeños, con dos hazas de secano en el Campillo pegadas a ellos ${ }^{24}$, a un cuarto de legua de la hacienda de Cordobilla, valorados en 30 ducados.

- La heredad de Torrepalma, a un cuarto de legua de Almuñécar, 7 marjales de riego inicialmente, reducidos a un pedazo grande de tierra de secano de erial, que antes estuvo de viña, y una haza de 3 marjales en el río Verde junto a la acequia, porque el resto se lo llevó el rio, comprada ${ }^{25}$ en 200 ducados y tasada en 400 reales.

En Jayena, localidad suroriental a $45 \mathrm{~km}$. de Granada, cuatro cortijos llamados de Santa Polonia ${ }^{26}$, lindando con el cortijo de Santa Pudia, la Malá, fuente de Pera y la mojonera de Jayena:

- cortijo de Santa Polonia, con casa, tasado en 6.173 reales; en 1638 se plantaron 200 árboles que costaron 600 reales.

- cortijos de la Fuente de don Pedro y Majadillas, valorados en 6.909 reales.

- cortijo de Peñaflor, en las canteras de Santa Pudia, tasado en 6.929 reales.

En Campotéjar, localidad a $45 \mathrm{~km}$. al norte de Granada:

- cortijo de Miravalles ${ }^{27}$, antes llamado del Jama ${ }^{28}, 337,5$ fanegas de secano con monte, casas, 323 árboles campales de encinas y quejigos, más otros

20. Adquiridos a los herederos de Cristóbal de Fuentes con carga censual de 18.000 mrs. de principal debida al fisco regio, redimida en la compra el 5 de mayo de 1631.

21. A Juan Camacho el 12 de enero de 1597.

22. Comprada a don Juan Pacheco, vecino y regidor de Lobres, anejo de Salobreña.

23. Vendida por Alonso Sánchez, vecino de Jete. En manda testamentaria dispuso que don Francisco de Granada Venegas Mellado, hijo natural de su hermano Diego, administre de por vida esta hacienda y la de Torrepalma.

24. Adquiridos a los herederos del licenciado Vigil de Quiñones.

25. A doña Catalina de Benavides, mujer de su hermano don Diego de Granada.

26. Comprados a la Hacienda Real mediante acuerdo con don Luis de Padilla, comisionado regio.

27. Adquirido en remate público de la Junta de Población de Granada en 22 de agosto de 1598.

28. Por Diego Hernández Xama, labrador morisco de Granada que tiempo atrás había sido su propietario, Luna Díaz 1989, p. 199, le asigna 300 fanegas de superficie. Por su parte baja lindaba con el cortijo de Garnafate, Garzón Pareja 1977, pp. 75, 79. 
pequeños, lindero con los cortijos de Gómez Herrera, del Burgalés y el Juncal, valorado en 12.375 reales, rentaba 50 fanegas de pan terciado.

- cortijo de Camporrey, 200 fanegas de secano con monte, la mitad, con casa, comprada antes de su segundo matrimonio y la otra mitad ya casado con doña Leonor Rodríguez de Fonseca ${ }^{29}$, tasado en 9.850 reales, rentaba 50 fanegas de pan terciado.

- cortijo de San Pedro de la Canaleja ${ }^{30}, 137,5$ fanegas de secano con monte, 80 encinas, chaparros y quejigos campales; antes llamado Bonilla, de 110 fanegas, había sido del trapero morisco Diego de Mendoza; lindero con tierras del mayorazgo de la Casa de Granada, cortijo de la Inquisición, cortijo de Ortigas, un cortijo de don Alonso Venegas Alarcón, cortijo del Rey, propiedad de Gaspar de Jerez, y un camino; al mismo le agregó 27 fanegas ${ }^{31}$ construyendo casa y dos tinados de techumbre; tasado en 7.700 reales, rentaba 50 fanegas de pan terciado.

- la mitad del cortijo de los Nogueroles, 164,5 fanegas de cultivo de cereales, con monte, casa, corral, ejidos y agua, comprado por 10.000 reales $^{32}$, lindante con las tierras de Campotéjar y con la otra mitad del mismo cortijo propiedad de don Bernabé de Zafra, tasado en 10.446 reales.

- la Haza Ajena ${ }^{33}$ en Dehesa Vieja, tierra calma de secano de 30 fanegas, lindera por todas partes con tierras del mayorazgo de la Casa de Granada, valorada en 6.600 reales.

Asimismo, era de su propiedad el fruto de las encinas, quejigos y chaparros de los cuatro cortijos jayenenses de Santa Polonia, valorado en 600 reales, mismo precio en que lo compró ${ }^{34}$.

Ya casado en segundas nupcias, don Pedro adquirió en 1607 y 1609 el señorío sobre Campotéjar y Jayena, y en 1638 la jurisdicción civil y criminal de ambos

29. Antes de su segundo matrimonio compró 125 fanegas y la mitad de la casa a Simón Lopez de las Vacas, vecino de Iznalloz, y, ya casado, las otras 75 fanegas y mitad de la casa a Martín Merino en 28 de julio de 1612 .

30. Comprado en remate público de la Junta de Población antes de su segundo matrimonio en fecha no mencionada.

31. Vendidas por Cristóbal García, vecino de Montejícar.

32. A María de Lomas, vecina de Noalejo, viuda de Gonzalo de Ochando, en 9 de diciembre en 1641 .

33. Adquirida a Fernando Álvarez Zapata, veinticuatro de Granada, el 15 de junio de 1620. Probablemente sean las dos hazas de tierra de hasta 30 fanegas que habían pertenecido al morisco Albotodo, vecino de Granada, Garzón Pareja 1977, p. 82.

34. A la Hacienda Real, escritura de venta con don Luis Gudiel de Peralta, del Consejo Supremo y comisionado regio, Granada 19 de febrero de 1638. Años antes, 4 de febrero de 1590, don Alonso de Granada había comprado el fruto de las encinas de Campotéjar y Jayena -venta en Vélez Málaga por Lafuente Vergara, juez y comisionado regio-, y transmitido el derecho a don Pedro como parte del pago de la herencia de la dote y arras de su madre doña María Manrique, con la condición de quedar siempre en el mayorazgo de la Casa pagando el titular de la misma su valor de 3.000 ducados, Salamanca López, Blázquez Ruz 2002, pp. 749-750. Su hermanastro y sucesor en la Casa y mayorazgo, don Fernando de Granada, vinculó este derecho abonando aquella cantidad que se adjudicó a la Obra Pía. 
lugares $^{35}$. Por la de Campotéjar, cuyas alcabalas había adquirido años antes ${ }^{36}$, de dos leguas y un quinto aproximadamente pagó 13.238 ducados, 3 reales y 24 maravedís, a 6.000 ducados la legua ${ }^{37}$, es decir 4.951 .138 mrs., más 1.100 ducados en medirla, tomar posesión, contradicción y autos que sobre ella hubo y otros gastos varios hasta sacar el privilegio. La jurisdicción era sobre los cortijos del mayorazgo de la Casa de Granada, los cortijos de Miravalles, Camporrey y San Pedro de la Canaleja, pero no el de los Nogueroles, bienes libres de media legua de extensión ${ }^{38}$ y 3.000 ducados de valor, los cortijos de Fuente el Manzano, la Inquisición y Las Rozas propiedad de su primo hermano don Gil de Granada Rengifo, el cortijo del Aguilarejo poseído por su hermanastro don Juan de Granada Venegas Ochoa, las 200 fanegas que este heredó de su tía doña Juana de Mendoza, y la Haza Ajena en Dehesa Vieja.

La jurisdicción de Jayena, de algo más de tres leguas, importó 19.772 ducados y 6 reales, a 6.250 ducados la legua, esto es 7.394 .936 mrs., a lo que hubo de sumar 2.500 ducados por medir y remedirla, tomar posesión, vencer la oposición de la ciudad de Alhama y sacar el privilegio. En su testamento, la asignó al Patronato y Obra Pía con un valor de 4.951.138 mrs., porque la jurisdicción de Campotéjar, que a su vez legó a su mujer, le había costado esta misma cantidad. Una manda testamentaria sorprendente la de transferir, aunque eran bienes libres y quizás por ello, una y otra jurisdicción, respetivamente, al Patronato y Obra Pía y a la marquesa una vez viuda, que hubo de ser impugnada y anulada, pues ambas jurisdicciones permanecieron en los titulares de la Casa y marquesado de Campotéjar.

Fuera de Granada, el primer marqués de Campotéjar poseyó en Cañavate (Cuenca) doce hazas con 55 almudes de siembra, de variado tamaño y cultivo de trigo y cebada, con un valor de 70.514 mrs., y cinco majuelos de viña con 4.800 vides, tasados en $116.800 \mathrm{mrs}$.

Cuadro 1. Propiedades rústicas en Cañavate (Cuenca), hazas de cultivo.

\begin{tabular}{|c|c|c|c|c|c|}
\hline CULTIVO & $\begin{array}{c}\text { ALMUDES } \\
\text { DE } \\
\text { SIEMBRA }\end{array}$ & SITUACIÓN & $\begin{array}{c}\text { TASACIÓN } \\
\text { POR } \\
\text { ALMUD }\end{array}$ & $\begin{array}{c}\text { VALOR } \\
\text { REALES }\end{array}$ & $\begin{array}{c}\text { VALOR } \\
\text { MRS. }\end{array}$ \\
\hline cebada & 4 & vega camino de Cañada Juncosa & $4 \mathrm{~d}$. & 176 & 5.984 \\
\hline cebada & 3 & vega camino de Cañada Juncosa & $4 \mathrm{~d}$. & 132 & 4.488 \\
\hline trigo & 12 & Cañada de las Doncellas & $20 \mathrm{r}$. & 240 & 8.160 \\
\hline
\end{tabular}

35. AMJ, Título de marqués de Campotéjar, doc. 75. Referencia en AGS, Mercedes y Privilegios, Soria Mesa 1995, pp. 112, 115; García Hernán 2010.

36. 12 de octubre de 1627 por 682.380 maravedís, considerando una renta de 22.746 mrs. anuales a 30.000 el millar.

37. A 6.400 ducados la legua en los territorios al sur el Tajo en el reinado de Felipe IV, Domínguez Ortiz 1964, p. 169.

38. Unos 2.700 metros considerando que la legua castellana quedó fijada en el siglo XVI en 20.000 pies castellanos, es decir, entre 5,572 y $5,914 \mathrm{~km}(5.572$ y $5.914 \mathrm{~m})$. 


\begin{tabular}{|c|c|c|c|c|c|}
\hline CULTIVO & $\begin{array}{c}\text { ALMUDES } \\
\text { DE } \\
\text { SIEMBRA }\end{array}$ & SITUACIÓN & $\begin{array}{c}\text { TASACIÓN } \\
\text { POR } \\
\text { ALMUD }\end{array}$ & $\begin{array}{c}\text { VALOR } \\
\text { REALES }\end{array}$ & $\begin{array}{c}\text { VALOR } \\
\text { MRS. }\end{array}$ \\
\hline cebada & 1 & $\begin{array}{c}\text { La Cerrada entre el río y la } \\
\text { acequia }\end{array}$ & $66 \mathrm{r}$. & 66 & 2.244 \\
\hline cebada & 3 & $\begin{array}{c}\text { Camino de Santa M del Campo, } \\
\text { junto al molino }\end{array}$ & $11 \mathrm{~d}$. & 364 & 12.375 \\
\hline cebada & 1 & La Saceda & $33 \mathrm{~d}$. & 364 & 12.375 \\
\hline trigo & 12 & Camino del castillo & $26 \mathrm{r}$. & 312 & 10.608 \\
\hline trigo & 3 & Cañada de Retamal & $2 \mathrm{~d}$. & 66 & 2.244 \\
\hline- & 7 & Rincón del arenal & $2 \mathrm{~d}$. & 154 & 5.236 \\
\hline cebada & 6 & Los Parrales & $20 \mathrm{r}$. & 120 & 4.080 \\
\hline cebada & 2 & Los Parrales & $20 \mathrm{r}$. & 40 & 1.360 \\
\hline cebada & 1 & Los Parrales & $40 \mathrm{r}$. & 40 & 1.360 \\
\hline TOTAL & & & & 2.074 & 70.514 \\
\hline
\end{tabular}

d. $=$ ducados; r. $=$ real.

Viñas

\begin{tabular}{|c|c|c|c|c|}
\hline CULTIVO & $\begin{array}{c}\mathrm{N}^{\circ} \\
\text { VIDES }\end{array}$ & SITUACIÓN & $\begin{array}{c}\text { TASACIÓN } \\
\text { CEPA EN } \\
\text { MRS. }\end{array}$ & $\begin{array}{c}\text { VALOR } \\
\text { TOTAL } \\
\text { MRS. }\end{array}$ \\
\hline viña & 2.000 & Camino de Cañavate a San Clemente & 28 & 56.000 \\
\hline viña & 1.200 & El Sotillo & 24 & 28.800 \\
\hline viña & 800 & Camino de Vara del Rey & 20 & 16.000 \\
\hline viña & 400 & Senda del Campo & 28 & 11.200 \\
\hline viña & 400 & Senda del Campo & 12 & 4.800 \\
\hline
\end{tabular}

El valor de los bienes personales de don Pedro de Granada antes de su segundo matrimonio más los heredados de su madre doña Maria Manrique era de 7.350.272 mrs. $^{39}$. A su fallecimiento, el cuerpo de hacienda de todos sus bienes propios y los adquiridos en régimen de gananciales ascendió a $30.568 .421 \mathrm{mrs}$, de los que descontados $1.038 .537 \mathrm{mrs}^{40}$, quedaron $29.529 .887 \mathrm{mrs}$., asignándose

39. Además de los bienes rústicos, un solar en la calle de la Cárcel en Granada, derecho de hacer una venta en Prado Redondo, una casa caída, por tanto solar, en la plaza de Almuñécar, el oficio de regidor en esta ciudad, un censo sobre los propios y rentas de Toledo, el oficio de veinticuatro de Granada, las alcaidías del Generalife y de la fortaleza de Almuñécar, dos censos contra Isabel Redondo y Pedro Montesinos en Cañavate, un tapiz y el resto del salario que se le debía por alcaide de Salobreña.

40. Por deudas, gastos de entierro y limosnas de misas, cera, lutos y demás gastos funerales, legados que hizo, dinero y trigo pagados a su paje don Juan de Granada, restitución de joyas y dinero a su mujer, gastos de la partición y liquidación de sus bienes, donativos a la Corona, salarios de abogados, concierto con el marqués de Guadalcázar sobre la villa de Huétor Santillán en cumplimiento de sentencia, liquidación de censo, alcance de cuentas a favor de don Francisco Arias del Castillo, 
al Patronato y Obra Pía 29.696.796 mrs., con un exceso de 166.912 mrs. que había de recibir la marquesa viuda.

Esta cantidad corresponde a las fincas rústicas antes mencionadas: Huerta Nueva y Baldíos del Generalife en Granada; en Campotéjar, la mitad del cortijo de los Nogueroles, los cortijos de Miravalles, Camporrey, San Pedro de la Canaleja y la Haza Ajena; en Jayena, los cortijos de Santa Polonia, Fuente de don Pedro, Majadillas y Peñaflor y el fruto de las encinas, quejigos y chaparros de los mismos; en Almuñecar, las heredades de Cordobilla, Torrepalma y unos bancales de tierra; 40 fanegas de tierra en Salobreña, media suerte de población en Restábal y el derecho de hacer una venta, que nunca levantó, en prado redondo (Campotéjar) ${ }^{41}$. Y en Cañavate toda la hacienda agrícola ya citada, más cinco tinajas con una capacidad de 200 arrobas de vino y una medida de media fanega para medir cereales ${ }^{42}$. La toma de posesión de todos ellos se llevó a cabo en 1654 por don Francisco de Granada Mellado como patrón y administrador de la Obra Pía.

\section{GESTIÓN Y ELEMENTOS DEL PATRIMONIO RÚSTICO}

Disponemos de estudios sobre el patrimonio nobiliario y su gestión por la aristocracia castellana en época moderna: estructura de ingresos y gastos, la administración de una Casa o Estado bajo un determinado titular, un periodo o coyuntura concreta, el impacto de la llamada crisis de la aristocracia, y algún resorte extraordinario de la administración financiera nobiliaria, pero escasos los centrados en el reino de Granada ${ }^{43}$.

mayordomo en Granada y Campotéjar, y por el premio y reducción a vellón del dinero en plata y joyas de oro y plata vigente en estos años.

41. Junto con estas heredades, se le asignaron al Patronato y Obra Pía: la regiduría perpetua de Almuñécar y la de Granada, un censo sobre los propios y rentas de Toledo, un juro de millones en Granada, una renta de por vida de 1. 073.524 mrs., la mitad de lo que el Consejo de Hacienda le debía por varios motivos, los gajes de gentilhombre de boca del rey y como mayordomo de la reina, un censo sobre el estado del duque de Alba, un juro sobre los puertos de Portugal, los réditos de un censo del marqués de Estepa, un depósito de 614.776 mrs. en don Alonso de Herrera depositario general de Granada, la mitad de un censo contra don Pedro Francisco de Alarcón, la alcaidía de Almuñécar y la mitad del sueldo de la misma, un censo contra don Rodrigo de Herrera, un solar, tiendas y casa en Granada, el mesón de Campotéjar, bienes muebles en Jayena, la mitad de la deuda de don Pedro Marquefa y de José Montes, deudas del príncipe de Esquilache y del duque de Pastrana, la mitad de los alcances contra don Francisco del Castillo, mayordomo en Granada y Campotéjar, contra Diego Jiménez de Flores, mayordomo en Jayena, Alonso Martínez Piqueras, mayordomo en Cañavate, dos escrituras de obligación de don Gil Rengifo, retratos, ropa de vestir y armas personales, aderezos de caballería, muebles diversos y tapices.

42. También se le adjudicaron al Patronato y Obra Pía, unas casas debajo de la iglesia en Cañavate, tasadas en 3.650 reales; otra casa junto a la iglesia 1.300 reales; un censo contra Isabel Redondo de 717 reales de principal, a razón de catorce mil el millar, sobre un molino harinero a renta en el río Cañavate, en el paso de los Nuevos, escriturado el 27 de febrero de 1603; censo de 40 ducados de principal, a veinte mil el millar, sobre un majuelo de 2.500 vides por el que recibía 2 ducados de renta al año, protocolizado el 29 de marzo de 1600; censo de 40 ducados de principal a veinte mil el millar, sobre una viña de 600 vides y huerto de 2 ducados de renta al año, escriturado el 19 de abril de 1607.

43. Amplia bibliografía en Gómez Vozmediano 2012, pp. 228-277. 
En lo que atañe a la gestión de su patrimonio rústico, los Granada Venegas optaron siempre, y el primer marqués no fue una excepción, por arrendar sus tierras más que explotarlas directamente. El marquesado de Campotéjar, al igual que otros muchos lugares y villas de la Corona, fue un señorío con su titular ausente al residir en la Corte, que delega en un mayordomo encargado del cuidado de sus bienes y de la recaudación y administración de las rentas derivadas de sus propiedades, ingresos que le permiten el alto nivel de gasto inherente a la vida cortesana.

Son tres los mayordomos de rentas, que se corresponden con otros tantos territorios -Granada-Campotéjar, Jayena y Cañavate (Cuenca)-, y también administradores simultáneamente al llevar cuenta y razón de las entradas y salidas de caudales, anotando el cargo de las personas que los entregan y la data de lo que abonan $^{44}$. Una administración relativamente cercana al titular de la Casa mediante la correspondencia epistolar y el control directo al fiscalizar su gestión hacendística al cabo de un periodo de tiempo, de variable duración, con el correspondiente alcance a favor o en contra derivado de su gerencia ${ }^{45}$.

Una inspección y control muy dilatado en el tiempo, pues don Francisco Arias del Castillo, mayordomo en Granada-Campotéjar, a quien don Pedro de Granada le encargó la hacienda porque le sirvió de paje desde que llegó a Granada, y después por ausencia y mal servicio de algunos administradores, no la había dado desde 1635; tampoco Diego Jiménez Flores, mayordomo en Jayena, desde 1634, ni asimismo Alonso Martín Piqueras, mayordomo en Cañavate, desde 1641, mandando en su testamento se les tome cuenta de su gestión hacendística. Los dos primeros, en 1644, percibían un salario en dinero de 600 reales anuales ${ }^{46}$, y también en especie.

Estos mayordomos son los representantes locales de don Pedro de Granada, hombres de su confianza, buenos administradores, aunque no siempre. Así, Francisco de Rivera y Pablo del Castillo terminaron deudores en las cuentas de su mayordomía con los consiguientes pleitos en su contra sobre la administración que habían llevado. Y el mal servicio de otros, lo constata el propio marqués de Campotéjar en su testamento al declarar que varios antiguos mayordomos le debían dinero por alcance de sus cuentas, con los que tenía pleitos mandando se les cobre lo que no habían pagado. Entre estos se encuentran don Pedro Marquefa, administrador y mayordomo de las rentas de Granada-Campotéjar hasta 1636, alcanzado en 2.309 reales con el posterior embargo y ejecución de bienes. O José Montes, recaudador que en 1641 se apropió de 3.629,5 reales con la consiguiente requisitoria para prenderle despachada por el gobernador de Campotéjar don Francisco Arias del Castillo.

Una década después de morir don Pedro de Granada, Henríquez de Jorquera ${ }^{47}$ afirma que en Campotéjar solo había cortijos y alquerías con jurisdicción sobre

44. Un manual práctico de la época, González Ferrando 2013.

45. García Luján 2013, pp. 54-56.

46. En este año, Francisco Arias del Castillo percibía de salario en dinero 1.846 reales por la administración de la hacienda de Granada y su comarca.

47. 1934, p. 174. 
las mismas, para manifestar acto seguido, en clara contradicción, que lo habitaban 300 vecinos con los anejos de Camporrey y Dehesa Vieja y Nueva. A partir de la documentación conocida, Campotéjar en el mejor de los casos era una cortijada, una alquería, esto es, una agrupación de casas, punto de referencia de los diversos cortijos que integraban el patrimonio fundiario de don Pedro de Granada, dedicados al cultivo de cereales, no por elección sino por la calidad de la tierra y su rentabilidad, con inexistencia de labor de huerta.

Inseparable de la tierra es la casa, alhorí y cobertizo, cercanos a ella, vivienda del labrador, almacén de los granos cosechados hasta su venta y albergue del ganado. Las existentes en Campotéjar en 1644 son descritas como casas de techumbre con su tinado; tinado nuevo de techumbre; casa de techumbre; casas de teja, tinado y corral; solían tener uno o dos cuerpos tejados. Su valor era diverso: una casa en la plaza, 1.540 reales; otra casa de techumbre, 700 reales; tinados de techumbre, 300 reales; casa de techumbre pequeña, 165 reales; casa de techumbre tomada a Fernando Abril por deuda de 746 reales, o casa de teja, tinados y corral, que perdió Juan de Lomas por su deuda con la hacienda marquesal, 1.100 reales por estar caídos los tinados.

Junto a ellas el imprescindible alhorí, que en 1643 almacenaba 1.383 fanegas 2,5 celemines de trigo y 239 fanegas 9 celemines de cebada ${ }^{48}$, el mesón con cuarto de caballeriza valorado en 500 ducados, y lindero con él la herrería y corral en 440 reales. Esta conlleva la existencia de ganado de labor en la explotación agraria; el inventario de bienes no menciona el equipo agrícola para trabajar, ninguna mención hay a arados, pero sí a animales de labranza, el bien más valioso ${ }^{49}$.

Suelo pobre y clima árido el de Campotéjar, agricultura de secano que impone el cultivo al tercio al dejar el campo un año en barbecho, se ara en el segundo y siembra al tercero, que hay que matizar con el conocimiento preciso de la calidad de las tierras y su labrantía proporcionado por el Catastro de Ensenada ${ }^{50}$, ya que poco o nada habían cambiado las características físicas y climatológicas entre 1643 y 1752 . En concreto, todas las tierras eran de sembradura por carecer de riego ${ }^{51}$, distinguiéndose tres calidades -superior, mediana e inferior- con cultivo alternativo de un año de siembra y dos de descanso. Junto a estas, una gran porción de tierras inútiles por naturaleza cubiertas de maleza. Se usaba la medida de fanega sembrándose una fanega de trigo en las de calidad superior, la mitad en las de mediana y tres celemines en las de calidad inferior. Las tierras superiores se cultivaban solo de trigo, sin interpolarlas con otros granos, dando cada fanega de tierra, con dos años de intermisión, cinco de trigo al tercer año. Las de mediana calidad se sembraban únicamente de cebada, sin interpolarlas con otros frutos

48. Dada la baja producción de estos cortijos cabe pensar que esta gran cantidad de grano almacenado incluiría el cosechado en los otros cortijos del mayorazgo.

49. En 1643 lo integraban 21 yeguas de varios colores -tordilla, castaña, negra, blanca y alazana- de entre cuatro y catorce años, y un caballo castaño de cuatro años valorado en 60 ducados.

50. http://pares.mcu.es/Catastro/servlets/ServletController. [12/11/2016].

51. Solo una huerta, perteneciente al mayorazgo de la Casa de Granada, había en 1598, y una fanega de huerta sin árbol alguno, que producía 150 reales al año, registra el Catastro de Ensenada en 1752. 
porque no los producían, rindiendo cada fanega, con dos años de cesación, cuatro fanegas de cebada al tercer año. Las inferiores solo servían para centeno y escaña produciendo, con dos años de interrupción, cuatro fanegas de centeno o escaña al año. La mayor parte de las tierras era de inferior calidad.

Ningunos árboles, salvo las encinas y quejigos de los montes con su fruto de la bellota; estas tierras labrantías que pertenecieron al primer marqués de Campotéjar, en 1752 lo eran del Patronato y Obra Pía y Patronato de Huérfanas que había instituido don Pedro de Granada en su testamento. Los cortijos propiedad de estos dos Patronatos producían 10 fanegas de bellotas, y las encinas y quejigos, con corta y poda cada veinte años, 100 reales al Patronato y Obra Pía, 200 al Patronato de Huérfanas y 1.000 reales al décimo marqués de Campotéjar don Juan Bautista Grimaldi. En este año de 1752, Cristóbal Contreras tenia arrendados los cortijos de Camporrey, San Pedro de la Canaleja y Miravalles, arruinados estos dos últimos, con un beneficio de 50 reales anuales por ser tierras inferiores e inútiles las que labra, y la Haza Ajena 15 reales al año a su arrendatario. En definitiva, tierras de mala calidad las de los cortijos del primer marqués de Campotéjar.

La población en ese mismo año era de 50 vecinos en la villa y 23 en las casas de campo o alquerías de su término; de las 60 casas habitables, 12 de teja y las restantes de chamizos y retamas, 9 arruinadas y 47 pertenecían a los vecinos, que pagaban una gallina al año al señor por el suelo en el que se levantaban. Hasta 27 labradores cultivaban las tierras por arriendo, a los que se les asigna un jornal diario de 2 reales y a sus hijos y sirvientes un real, pues al no haber viña ni olivar era muy corto el tiempo en el que podían trabajar. Misma penuria que sufrían hasta 56 jornaleros con un jornal de un real diario. Como un siglo antes, un solo herrador ejercía su oficio en 1752 con tan poco trabajo que se le consideraba mero jornalero. La casa mesón rentaba 1.500 reales anuales a su propietario el décimo marqués de Campotéjar y 1.000 al mesonero que la gobernaba. Un único horno de pan cocer y una taberna.

En 1587 Jayena contaba con 16 vecinos ${ }^{52}, 20$ en $1609^{53}$ y 200 , cifra nada creíble, pocos años después de fallecer don Pedro de Granada Venegas ${ }^{54}$. El Catastro de Ensenada ${ }^{55}$ contabiliza 121 vecinos en 1752 con una sola casa de campo -Corzola- en su jurisdicción, 112 casas habitables que pagaban censo por razón de señorío a don Juan Bautista Grimaldi, 136 labradores y jornaleros con un ingreso de 2 reales diarios por día trabajado, un mesón y una tienda.

A diferencia de Campotéjar, las tierras de Jayena eran de mejor naturaleza; las de regadío solo de sembradura, con tres pequeños bosques, produciendo las de primera calidad una cosecha anual y las de segunda y tercera un año sí y otro descansaban. Las tierras de secano unas eran de sementera y otras de matorrales y montes, cuyos pastos el marqués don Juan Bautista Grimaldi vendía a forasteros, aunque permitía a los vecinos tener el ganado sin pago alguno. Las tierras de seca-

52. Ruiz Martín 1968, p. 175.

53. Soria Mesa 1995, p. 115.

54. Henríquez de Jorquera 1934, pp. 148-149.

55. http://pares.mcu.es/Catastro/servlets/ServletController. Jayena. [13/12/2016]. 
no de superior calidad producían un año y descansaban otro, pero las de segunda y tercera necesitaban dos, tres y más años de intermisión. Las de cuarta calidad era la tierra inútil, esto es, montes, aulagas y atochares con sus correspondientes pastos. Tanto en las tierras de secano como en las montuosas y sierras crecían quejigos, encinas, robles, pinos negrales y $\operatorname{carrascos}^{56}$.

Como lugar de señorío, Jayena y su jurisdicción pertenecían al décimo marqués de Campotéjar, que en 1752 no percibía derechos algunos a excepción del quinto de los frutos recogidos y los censos y adehalas que los vecinos le pagaban por los solares de las casas, rentas de unos 11.000 reales al año.

\section{LAS RENTAS}

La fortuna y patrimonio de don Pedro de Granada Venegas descansa en dos ejes; uno, como tantos otros nobles y señores castellanos, el mayorazgo de su Casa antes mencionado y como tal inalienable; otro, los bienes libres y gananciales que adquirió a lo largo de su vida, que constituyen un cuerpo de hacienda del que disponer libérrimamente en sus últimas voluntades, como así hizo. Estos bienes rústicos los compra en comarcas con las que tiene una fuerte vinculación previa: Granada ciudad y cercanías, su residencia hasta su traslado definitivo a Madrid en 1619; Campotéjar, en el importante eje viario de Granada a Jaén, donde como mayorazgo de la Casa poseía importantes predios rústicos ya relacionados; Jayena, lugar vinculado también al mayorazgo en 1535 al casar su abuelo don Pedro de Granada Mendoza con doña María Rengifo Dávila, que la aportó al matrimonio; Salobreña y Almuñécar, de cuyas fortalezas fue alcaide y regidor, y Cañavate (Cuenca) por su abuela doña María de Mendoza y madre doña María Manrique.

Sabemos de la existencia de libros de registro con las haciendas de Granada, Campotéjar, Jayena y Cañavate, de grandes volúmenes de a folio en los que se halla anotado todo el patrimonio del primer marqués de Campotéjar, así como libros de contabilidad, de gasto, de entradas y salidas de dinero, de cuenta, cargo y descargo de mayordomos desde 1613. El problema radica en que esta documentación y toda la restante del rico archivo del marquesado de Campotéjar se encuentra inaccesible desde hace un siglo en Italia, sin ni siquiera haberse inventariado ${ }^{57}$.

Por ello, para el análisis de las rentas de estos predio rústicos, no vinculados al mayorazgo, hay que ceñirse a la cuenta tomada a los mayordomos de estos partidos por los testamentarios de don Pedro de Granada, correspondiente al pe-

56. En el término de Jayena había unas 4.700 fanegas de tierra de cuerda, de ellas 150 de riego, y de estas 50 fanegas de primera calidad, 50 de segunda y 50 de tercera calidad. Las 4.550 fanegas restantes eran de secano, y de ellas, 838 fanegas de cultivo y labor, de las cuales 200 fanegas eran de primera calidad, 280 de segunda y 358 de tercera calidad. Las restantes 3.712 fanegas eran montuosas e incultas por su naturaleza, solo útiles para pastos junto con el fruto de los árboles que las poblaban.

57. García Luján 2013, pp. 37-38. 
riodo desde el 6 de febrero de 1643, día inmediato a su fallecimiento, hasta el 31 de diciembre de 1644, dentro del inventario, tasación y adjudicación de bienes llevado a cabo para cumplir sus últimas voluntades. Haciendas entregadas para su explotación a labor a cambio de rentas, que en ese espacio de tiempo fueron:

Cuadro 2. Rentas de las tierras. Campotéjar y Jayena. Pan terciado 6 de febrero 1643 a 31 diciembre 1644.

\begin{tabular}{|c|c|c|c|c|c|c|}
\hline AÑO & PARTIDO & CORTIJO & TRIGO & CEBADA & CENTENO & $\begin{array}{c}\text { ARRENDA- } \\
\text { TARIO }\end{array}$ \\
\hline 1643 & Campotéjar & Camporrey & $22 \mathrm{f} .8 \mathrm{c}$. & 11f. 4c. & & $\begin{array}{c}\text { Francisco } \\
\text { Lomas }\end{array}$ \\
\hline 1643 & Campotéjar & Miravalles & $18 \mathrm{f} .8 \mathrm{c}$. & 9f. $4 \mathrm{c}$. & & $\begin{array}{l}\text { Diego de } \\
\text { Ochando }\end{array}$ \\
\hline 1643 & Iznalloz & La Canaleja & $26 \mathrm{f} .8 \mathrm{c}$. & 13f. 4c. & & $\begin{array}{c}\text { Francisco } \\
\text { Ramos }\end{array}$ \\
\hline 1643 & Dehesa Vieja & Haza Ajena & & & & No hubo \\
\hline 1643 & Iznalloz & Los Nogueroles & & & & No hubo \\
\hline 1644 & $\begin{array}{c}\text { Campotéjar } \\
\text { Iznalloz } \\
\text { Dehesa Vieja }\end{array}$ & $\begin{array}{c}\text { Camporrey, } \\
\text { Miravalles, La Ca- } \\
\text { naleja } \\
\text { Haza Ajena }\end{array}$ & 87f. 4c. & 41f. 8c. & & Desconocido \\
\hline 1643 & Jayena & $\begin{array}{c}\text { Santa Polonia } \\
\text { Peñaflor } \\
\text { Fuente de don } \\
\text { Pedro-Majadillas }\end{array}$ & $100 f$. & $11 \mathrm{f}$. & & Desconocido \\
\hline 1644 & Jayena & $\begin{array}{c}\text { Santa Polonia } \\
\text { Peñaflor } \\
\text { Fuente de don } \\
\text { Pedro-Majadillas }\end{array}$ & $118 \mathrm{f}$. & 30f. 3c. & $4 \mathrm{f}$. & Desconocido \\
\hline
\end{tabular}

f. = fanega; c. = celemín.

Por tanto, el monto o cargo total en este bienio fue de 373 fanegas 4 celemines de trigo, 116 fanegas 11 celemines de cebada y 4 fanegas de centeno; descontando de las mismas, 24 fanegas de trigo y 12 de cebada por el podrido y comido de ratones en el alhorí de Jayena, y 66 fanegas 10 celemines de trigo y 79 fanegas 5 celemines de cebada como salario en especie de los tres mayordomos ${ }^{58}$, el resultado neto fue de 282,5 fanegas de trigo, 37,5 fanegas de cebada y 4 de centeno $^{59}$;

58. Don Francisco Arias del Castillo, mayordomo en Granada y Campotéjar, 20 fanegas de trigo y 27 fanegas y 5 celemines de cebada, más 1 celemín de cebada para el mulo con el que se desplazaba para cobrar las rentas. Diego Jiménez de Flores, mayordomo en Jayena, 32 fanegas de trigo y 40 fanegas de cebada. Alonso Martínez Piqueras, mayordomo en Cañavate, 14 fanegas y 10 celemines de trigo.

59. No hay mención a otras semillas y herbáceas, que por escasa, si la hubo, no se cuantifica. 
reducidas a dinero, a razón de 18 reales la fanega de trigo, 9 la de cebada y la de centeno a 11 reales, arrojan un total de 5.466,5 reales. Extraña que el precio de venta sea el de la tasa, cuando en 1634, tras las catastróficas cosechan de comienzos de esta década, la fanega de trigo alcanzó los 40 reales $^{60}$. No se menciona el mijo, habas, garbanzos, cáñamo y seda de los cuatro cortijos de Santa Polonia en Jayena porque no los hubo en estos dos años, pero sí 67 arrobas de cáñamo agramado a 18 reales la arroba -1.206 reales-, y 25,5 arrobas de lino espadado ${ }^{61}$ a 25 reales la arroba $-637,5$ reales- en 1643. Dos husillos para exprimir cera indican la práctica de la apicultura.

Y agregado como obligatorio a la renta de los cortijos, las adehalas, precisadas para los de Campotéjar, pero no los de Jayena, en este bienio de 1643-1644.

Cuadro 3. Adehalas de los renteros. Campotéjar. 6 de febrero 1643 a 31 diciembre 1644.

\begin{tabular}{|c|c|c|c|c|c|c|}
\hline AÑO & PARTIDO & CORTIJO & TIPO/ESPECIE & $\begin{array}{l}\text { VALOR } \\
\text { UNIDAD }\end{array}$ & $\begin{array}{l}\text { VALOR } \\
\text { TOTAL } \\
\text { MRS. }\end{array}$ & RENTEROS \\
\hline 1643 & Campotéjar & & $\begin{array}{c}\text { adehala de monte, } \\
\text { arriendo de } 27 \\
\text { yuntas }\end{array}$ & $\begin{array}{l}38 \mathrm{r} .1 \mathrm{c} . \\
\text { por yunta }\end{array}$ & 31.648 & De la villa \\
\hline 1644 & Campotéjar & & $\begin{array}{c}\text { adehala de monte, } \\
\text { arriendo de } 27 \\
\text { yuntas }\end{array}$ & $\begin{array}{l}38 \mathrm{r} .1 \mathrm{c} . \\
\text { por yunta }\end{array}$ & 35.112 & De la villa \\
\hline 1643 & Campotéjar & & $\begin{array}{c}27 \text { gallinas } \\
\text { adehala del monte }\end{array}$ & $4 \mathrm{r}$. & 3.309 & $\begin{array}{l}\text { Vecinos de } \\
\text { Campotéjar }\end{array}$ \\
\hline 1644 & Campotéjar & & $\begin{array}{c}27 \text { gallinas } \\
\text { adehala del monte }\end{array}$ & $4 \mathrm{r}$. & 3.672 & $\begin{array}{l}\text { Vecinos de } \\
\text { Campotéjar }\end{array}$ \\
\hline 1643 & $\begin{array}{c}\text { Iznalloz } \\
\text { Campotéjar }\end{array}$ & $\begin{array}{l}\text { La Cana- } \\
\text { leja Mira- } \\
\text { valles }\end{array}$ & 4 gallinas & $4 \mathrm{r}$. & 490 & $\begin{array}{l}\text { Renteros de } \\
\text { los cortijos }\end{array}$ \\
\hline 1644 & $\begin{array}{c}\text { Izanalloz } \\
\text { Campotéjar }\end{array}$ & $\begin{array}{l}\text { La Cana- } \\
\text { leja Mira- } \\
\text { valles }\end{array}$ & 4 gallinas & $4 \mathrm{r}$. & 544 & $\begin{array}{l}\text { Renteros de } \\
\text { los cortijos }\end{array}$ \\
\hline TOTAL & & & & & 90.678 & \\
\hline
\end{tabular}

d. $=$ ducados; $\mathrm{r} .=$ real; $\mathrm{c} .=$ cuartillo.

A estos ingresos por los arrendamientos de los cortijos y adehalas hay que añadir la renta de la bellota del monte de Jayena, arrendada en 2.000 reales en 1643 y a la mitad un año después $-61.293 \mathrm{mrs}$. y $34.000 \mathrm{mrs}$. respectivamente ${ }^{62}$.

60. En 1752, Catastro de Ensenada, los precios seguían casi invariables: 18 reales la fanega de trigo, 9 la de cebada, 14 la de centeno, 6 la de escaña y 3 reales la de bellota.

61. Para estos procesos, agramado y espadado, González Bachiller 1992, pp. 12-13.

62. Prorrata de 329 días a contar desde el 6 de febrero de ese año. 
En cuanto a la Huerta Nueva, Granada, su arriendo de 40 ducados anuales generó 13.484 mrs. y 14.960 mrs. en uno y otro año, y los viñedos de Cañavate (Cuenca) una cantidad similar -11.379 mrs.- en el mismo bienio.

Cuadro 4. Rentas en Cañavate. 6 de febrero 1643 a 31 diciembre 1644.

\begin{tabular}{|c|c|c|c|}
\hline RENTERO & CEPAS DE VIÑA & $\begin{array}{c}\text { RENTA ANUAL } \\
\text { REALES }\end{array}$ & $\begin{array}{c}\text { RENTA BIENAL } \\
\text { MRS. }\end{array}$ \\
\hline Juan Molina & 600 & $22^{*}$ & 1.422 \\
\hline Andrés Molina & $\begin{array}{c}400 \text { en senda del } \\
\text { Campo }\end{array}$ & 16 & 1.035 \\
\hline Juan Delicado & 500 & 18 & 1.164 \\
\hline $\begin{array}{c}\text { Alonso Martínez, } \\
\text { mayordomo }\end{array}$ & $\begin{array}{c}2.000 \text { término de San } \\
\text { Clemente }\end{array}$ & 60 & 3.879 \\
\hline $\begin{array}{c}\text { Alonso Lozano } \\
\text { Vara del Rey }\end{array}$ & 60 & 11.379 \\
\hline Total & \begin{tabular}{c} 
2.000 camino de \\
\hline
\end{tabular}
\end{tabular}

* Por censo de 40 ducados de principal a veinte mil el millar, sobre esta viña y huerto de 2 ducados de renta al año, escriturado el 19 de abril de 1607.

Por tanto, el total de ingresos, sistematizados en el cuadro siguiente, que generaron los bienes rústicos privados, no amayorazgados, en estos dos años fue de 474.334 mrs., de los que descontados $1.756,8$ reales $\left(59.731 \mathrm{mrs}\right.$.) de gastos ${ }^{63}$, arroja un saldo positivo de 414.603 mrs. (1.108 ducados).

Cuadro 5. Renta total de los bienes rústicos. 6 de febrero 1643 a 31 diciembre 1644 .

\begin{tabular}{|c|c|c|c|c|c|}
\hline & $1643-44$ & CORTIJOS & PRECIO & IMPORTE & $\begin{array}{c}\text { VALOR } \\
\text { MRS. }\end{array}$ \\
\hline Trigo & $282,5 \mathrm{f.}$ & $\begin{array}{c}\text { 1643: Camporrey, Miravalles } \\
\text { La Canaleja* } \\
\text { 1644: Haza Ajena, Camporrey, La } \\
\text { Canaleja** } \\
\text { Jayena: cortijos de Santa Polonia }\end{array}$ & $18 \mathrm{r} / \mathrm{f}$. & $5.085 \mathrm{r}$. & 172.890 \\
\hline
\end{tabular}

63. De 6 febrero 1643 a 31 diciembre 1644: reparos en Camporrey, Miravalles y San Pedro de la Canaleja (Campotéjar), 380 reales; trilla de las yeguas en este mismo lugar, 330 reales; cobro de las rentas de trigo y cebada en los cortijos de Santa Polonia (Jayena) 132 reales; salario en dinero a Diego Jiménez, mayordomo en Jayena, 840,8 reales; inspección y autos hechos por la esterilidad del año, 74 reales. 


\begin{tabular}{|c|c|c|c|c|c|}
\hline & $1643-44$ & CORTIJOS & PRECIO & IMPORTE & $\begin{array}{c}\text { VALOR } \\
\text { MRS. }\end{array}$ \\
\hline Cebada & $37,5 \mathrm{f}$. & $\begin{array}{c}\text { 1643: Camporrey, Miravalles } \\
\text { La Canaleja* } \\
\text { 1644: Haza Ajena, Camporrey, La } \\
\text { Canaleja, Miravalles** } \\
\text { Jayena: cortijos de Santa Polonia }\end{array}$ & 9r./f. & 337,5 r. & 11.475 \\
\hline Centeno & $4 \mathrm{f}$. & Jayena: cortijos de Santa Polonia & 11r./f. & $44 \mathrm{r}$. & 1.496 \\
\hline $\begin{array}{c}\text { Cañamo } \\
\text { agramado }\end{array}$ & 67 ar. & Jayena & 18r./ar. & $1.206 \mathrm{r}$. & 41.004 \\
\hline $\begin{array}{l}\text { Cáñamo } \\
\text { espadado }\end{array}$ & 25,5 ar. & Jayena & $25 \mathrm{r} / \mathrm{ar}$. & $637,5 \mathrm{r}$. & 21.675 \\
\hline Adehalas & & Campotéjar & & & 90.678 \\
\hline Monte & & Jayena & & $\begin{array}{l}2.000 \mathrm{r} / \mathrm{añ} . \\
1.000 \mathrm{r} / \mathrm{añ} .\end{array}$ & $\begin{array}{l}61.293 \\
34.000\end{array}$ \\
\hline Viñas & & Cañavate & & & 11.379 \\
\hline Hazas & & Canavate & & Ninguno & \\
\hline Huerta & & Granada: Huerta Nueva & & 40d./añ. & 28.444 \\
\hline Total & & & & & 474.334 \\
\hline
\end{tabular}

*La Haza Ajena y Los Nogueroles sin arrendar en 1643. ** Los Nogueroles sin arrendar en 1644 o en barbecho.

añ. $=$ año; ar. $=$ arroba $;$ d. $=$ ducado $;$ f. $=$ fanega $;$ r. $=$ real.

\section{CONCLUSIONES}

En las páginas precedentes se ha analizado el patrimonio personal rústico que adquirió don Pedro de Granada Venegas Manrique, primer marqués de Campotéjar, desde finales del siglo XVI hasta poco antes de su muerte en 1643, hacienda desconocida de la que teníamos alguna referencia bibliográfica o documental. El grueso de las heredades se concentra en Campotéjar con 900 fanegas de tierra y, considerando la tasación judicial con un valor medio aproximado de 40 reales la fanega, unas 500 en Jayena -155 el cortijo de Santa Polonia, y en torno a las 175 fanegas los de Fuente don Pedro-Majadillas y Peñaflor- lugares en los que desde principios del siglo XVI la Casa de Granada poseía grandes propiedades vinculadas al mayorazgo.

Los heredamientos en Campotejar, con un valor de 4.270 ducados, representan el 55,7\% de las compras, los de Jayena, tasados en 1.819 ducados, el 23,7\%, correspondiendo el 20,5\% restante -1.577 ducados- a los predios situados en Granada, Almuñécar y Salobreña.

Parte de estos bienes raíces - cortijos de Miravalles y San Pedro de la Canaleja- fueron comprados a la Junta de Población de Granada en la venta de propiedades moriscas a subasta por la Corona, ramo de censos sueltos, después de la guerra 
de las Alpujarras y la real provisión de 24 de febrero de 1571 por la que se les confiscaban todas sus posesiones. Otra parte, los cuatro cortijos de Santa Polonia en Jayena, lo fue a la Hacienda Real, acuciada financieramente y necesitada de recursos para subvenir la política imperial.

Aunque pudo hacerlo, don Pedro de Granada no agregó ninguna de estas heredades al mayorazgo para incrementar el patrimonio de la Casa de Granada, probablemente por carecer de descendencia y ser sus sucesores dos hermanastros con los que siempre hubo desapego mutuo, enfrentado en los tribunales con Fernando, chantre de la catedral de Cuenca, y con escasa empatía hacia Juan de Granada Venegas Ochoa.

La compra en 1632 de las jurisdicciones de Campotéjar y Jayena por 6.000 y 6.250 ducados la legua, conforme a la superficie del término, no por el número de habitantes de estos lugares casi despoblados, es algo inferior al precio a que se vendieron las jurisdicciones al sur del Tajo en el reinado de Felipe IV. Una venta de jurisdicción directa, sin que mediara deuda o alcance de don Pedro de Granada con la Corona, a la que se opusieron, no sabemos con qué fuerza, los cabildos de Granada y Alhama que no consiguieron frenarla. La jurisdicción incluía el derecho de construir una venta en prado redondo, esto es, dentro de los predios de un mismo dueño que no incluyen en sus linderos heredad ajena.

El señorío jurisdiccional incluía el nombramiento de un juez señorial, función que desempeñaba el mayordomo, llamado a veces gobernador, de los partidos de Granada-Campotéjar y de Jayena; ejercido solo una década, desde 1632 en que obtuvo la jurisdicción hasta su muerte en 1643, contados son los datos que proporciona la tasación judicial de bienes y derechos: casa de cabildo y cárcel en Campotéjar; una escribanía pública en esta villa y en Jayena; al año, 100 ducados las alcabalas y 330 reales las alcabalas del viento en Campotéjar; 25 reales anualmente las penas de Cámara en Jayena, y el derecho del uno por ciento de las ventas y el dos de lo arrendable.

Se trata de fincas rústicas de diverso tamaño con predominio de los cortijos de secadal en Campotéjar y Jayena, explotaciones de mediana extensión sobre tierras de labor y monte, es decir, fincas y caseríos dedicados a la agricultura cerealista extensiva en tierras de sequero. Campos pobres y de secano, salvo alguna heredad de huerta, dedicados a los cereales con predominio del trigo seguido a distancia por la cebada y aún mucho más por el centeno, siendo menor el cultivo de otras semillas -escanda, garbanzos, mijo, yeros, linaza-. Por tanto, agricultura de baja rentabilidad en tierras cultivadas a renta por labradores con un hábitat disperso en torno a un cortijo - cortijadas, cortijos-aldea-.

Un patrimonio rústico amplio, pero concentrado, sin una compleja estructura administrativa que aumente los gastos; no hay contadores, ni tesoreros, secretarios u otros oficiales - un mayordomo, secretario, capellán, dos pajes y tres criados era el personal a su servicio en Madrid-, sí tres mayordomos-administradores, uno para cada uno de los tres partidos en que se localizan las haciendas privadas de don Pedro de Granada y las del mayorazgo de la Casa, cuya gestión y toma de 
cuentas fiscaliza personalmente; nada que ver, pues, con señoríos coetáneos de mayor entidad.

Como otros muchos compradores de lugares, aldeas y villas, el prestigio y honor para sí mismo y para su Casa fue el móvil que le impulsó para, mediante una estrategia planificada, conseguir las alcabalas primero, el señorío jurisdiccional después y, finalmente, un título de nobleza.

Sin hijos que lo heredaran, don Pedro de Granada legó este gran patrimonio rústico personal, no amayorazgado, al Patronato y Obra Pía que instituyó en su testamento, y con sus rentas cumplir las mandas testamentarias para beneficio de su alma como única y universal heredera en la confianza de alcanzar la salvación eterna.

\section{BIBLIOGRAFÍA}

Álvarez Márquez, María del Carmen; García Luján, José Antonio (2008), "Las lecturas de don Pedro de Granada Venegas, I marqués de Campotéjar (15591643)" Historia. Instituciones. Documentos, 35, pp. 149-158.

Álvarez-Osorio Alvariño, Antonio (1998), "Corte y cortesanos en la Monarquía de España", Patrizi, Giorgio; Quondam Amedeo (coord.), Educare il corpo, educare la parola, Roma, pp. 297-365.

Cabrera de Córdoba, Luis (1998), Historia de Felipe II rey de España, Salamanca.

Casey, James (2008), Familia, poder y comunidad en la España Moderna. Los ciudadanos de Granada (1570-1739), Valencia.

Domínguez Ortiz, Antonio (1964), "Ventas y exenciones de lugares durante el reinado de Felipe IV", Anuario de historia del derecho español, 34, pp. 163-207. Reimpresión en Domínguez Ortiz, Antonio (1985), Instituciones y sociedad en la España de los Austrias, Barcelona.

García Hernán David (2010), El gobierno señorial en Castilla. La presión y concesión nobiliaria en sus documentos (siglos XVI-XVIII), Madrid.

García Luján, José Antonio (2002), "Don Pedro de Granada Venegas, I marqués de Campotéjar (1643), de Campo Rey y vizconde de Miravalles (1632)", VIII Simposio Internacional de mudejarismo. De mudéjares a moriscos: una conversión forzada, Teruel, pp. 721-731.

García Luján, José Antonio (2010), “Genealogía del linaje Granada Venegas desde Yusuf IV, rey de Granada (1432), hasta la extinción de la varonía del linaje (1660)", García Luján, José Antonio (ed.), Nobleza y Monarquía. Los linajes nobiliarios en el Reino de Granada, siglos XV-XIX. El linaje Granada Venegas, Marqueses de Campotéjar, Granada, pp. 13-43.

García Luján, José Antonio (2013), "La memoria escrita de la Casa de Granada: el archivo del marquesado de Campotéjar (s. xv-1643)", Historia. Instituciones. Documentos, 40, pp. 35-79.

Garzón Pareja, Manuel (1977), "Cortijos del término de Granada que pertenecían a moriscos", Cuadernos de la Alhambra, 13, pp. 63-83. 
Gómez Vozmediano, Miguel (2012), "La gestión patrimonial de la aristocracia castellana. Burocracia señorial, práctica contable y reflejo documental (siglos XV-XVIII)", Alloza Aparicio, Ángel; Fernández Izquierdo Francisco; García Guerra, Elena (eds.), Comercio, banca y sociedad en los reinos hispánicos (siglos XIV-XVIII), Madrid, pp. 228-277.

González Bachiller, Fabián (1992), "Vocabulario del cáñamo y sus labores en Cervera del Río Alhama (La Rioja)", Berceo, 122, pp. 7-44.

González Ferrando, José María (2013), "Un manual español de administración y contabilidad señorial de principios de siglo XVII: el compendio en materia de acrecentar Estado y hazienda, tocante al oficio de contador, de Gabriel Pérez del Barrio Angulo", De computis. Revista española de historia de la contabilidad. Spanish Journal of Accounting History, 19, pp. 94-152.

Henríquez de Jorquera, Francisco (1934), Anales de Granada. Edición preparada, según el manuscrito original, por A. Marín Ocete, Granada.

Luna Díaz, Juan Andrés (1989), "Repoblación y gran propiedad en la región de los Montes de Granada durante el siglo XVI. El cortijo", Chronica Nova, 17, pp. 171-204.

Maravall, José Antonio (2007), Poder, honor y élites en el siglo XVII, Madrid.

Peinado Santaella, Rafael (1989a), "Los orígenes del marquesado de Campotéjar (1514-1632). Una contribución al estudio de los señoríos del Reino de Granada", Chronica Nova, 17, pp. 261-279.

Peinado Santaella, Rafael (1989b), La repoblación de la tierra de Granada. Los Montes Orientales (1485-1525), Granada.

Peinado Santaella, Rafael; Osorio Pérez, María José (2006), "Las bases materiales de la oligarquía granadina: el patrimonio de don Alonso Venegas", Chronica Nova, 32, pp. 269-287.

Ruiz Martín, Felipe (1968), “Movimientos demográficos y económicos en el reino de Granada durante la segunda mitad del siglo XVI", Anuario de historia económica y social, 1, pp. 127-183.

Salamanca López, Manuel; Blázquez Ruz, Ricardo (2002), "El linaje Granada Venegas: un pleito de familia a principios del siglo XVII”, VIII Simposio Internacional de Mudejarismo. De mudéjares a moriscos: una conversión forzada, Teruel, pp. 747-751.

Soria Mesa, Enrique (1995), La venta de señoríos en el reino de Granada bajo los Austrias, Granada.

Soria Mesa, Enrique (1997), Señores y oligarcas: los señoríos del reino de Granda en la Edad Moderna, Granada.

Fecha de recepción del artículo: 7 de febrero de 2017

Fecha de aceptación y versión final: 4 de abril de 2017 